\title{
Fontes de óleo na dieta e sua influência no desempenho e na imunidade de frangos de corte ${ }^{1}$
}

\author{
Marcos F. Pinto ${ }^{2 *}$, Valéria M.F. Lima ${ }^{3}$, Sheila C. Ribeiro ${ }^{4}$, Iderlipes L.C. Bossolani ${ }^{4}$, \\ Elisa H.G. Ponsano ${ }^{2}$ e Manoel Garcia-Neto ${ }^{2}$
}

\begin{abstract}
Pinto M.F., Lima V.M.F., Ribeiro S.C., Bossolani I.L.C., Ponsano E.H.G. \& Garcia-Neto M. 2014. [Sources of oil in the diet and its influence on the performance and the immunity of broilers.] Fontes de óleo na dieta e sua influência no desempenho e na imunidade de frangos de corte. Pesquisa Veterinária Brasileira 34(5):409-414. Programa de Pós-Graduação em Ciência Animal, Faculdade de Medicina Veterinária de Araçatuba, Universidade Estadual Paulista "Júlio de Mesquita Filho", Rua Clóvis Pestana 793, Araçatuba, SP 16050-680, Brazil. E-mail: hipiatra@gmail.com

The fatty acid composition in the diet can affect the productive performance and the immune system of broiler chickens. The objective of this study was to evaluate the effect of the consumption of oils rich in omega-6 (n-6 PUFA) and omega-3 (n-3 PUFA) polyunsaturated fatty acids on the performance and the immune response of broilers submitted to an antigenic challenge. Diets were formulated with either $7 \%$ soybean oil (SO), linseed oil (LO) or sardine oil (PO) and provided to 240 Cobb broilers which were divided into 24 groups of 10 birds each, following a 3x2 experimental arrangement ( 3 types of oil and vaccinated or non-vaccinated birds) and four replications. Soybean oil is rich in linoleic acid (n-6 PUFA), linseed oil a source of alfa-linolenic acid (n-3 PUFA) and the sardine oil is a source of eicosapentaenoic and docosahexaenoic acids (other n-3 PUFA). Feed intake, weight gain and feed conversion were evaluated at 21, 35 and 42 days. Half of the birds were vaccinated against Newcastle disease at 7 and 21 days. Fifteen days after the immunization, the production of antibodies was evaluated by ELISA and expressed by optical density at $450 \mathrm{~nm}$ (O.D. $450 \mathrm{~nm}$ ). Only the birds fed ration containing SO presented higher humoral immune response $(\mathrm{p}<0.05)$ after vaccination. The lymphoproliferative response, which expresses the cellular immunity, was higher in vaccinated than in the unvaccinated birds $(\mathrm{P}<0.05)$, regardless of the oil used. Neither the oil source in the ration nor the vaccination influenced birds' weight gain $(\mathrm{P}>0.05)$. The vaccination impaired the feed conversion of the birds fed diet containing SO $(\mathrm{P}<0.05)$ but did not influence feed conversion of the birds fed rations with LO or PO (P>0.05). The use of oil rich in n-6 PUFA in broilers' diet increased humoral response, but did not influence the cellular response against an antigenic challenge.
\end{abstract}

INDEX TERMS: Linseed oil, sardine oil, soybean oil, cellular immune response, humoral immune response.

\footnotetext{
${ }^{1}$ Recebido em 13 de fevereiro de 2014.

Aceito para a publicação em 17 de abril de 2014.

${ }^{2}$ Departamento de Apoio, Produção e Saúde Animal, Faculdade de Medicina Veterinária de Araçatuba (FMVA), Universidade Estadual Paulista (Unesp), Rua Clóvis Pestana 793, Araçatuba, SP 16050-680, Brasil. *Autor para correspondência: hipiatra@gmail.com

${ }^{3}$ Departamento de Clínica, Cirurgia e Reprodução Animal, FMVA-Unesp, Rua Clóvis Pestana 793, Araçatuba, SP.

${ }^{4}$ Programa de Pós-Graduação em Ciência Animal, FMVA-Unesp, Rua Clóvis Pestana 793, Araçatuba, SP.
}

RESUMO.- A composição de ácidos graxos da dieta pode influenciar o desempenho produtivo e o sistema imune de frangos de corte. 0 objetivo deste estudo foi avaliar o efeito do consumo de óleos ricos em ácidos graxos poli-insaturados ômega-6 (PUFAs n-6) e ômega-3 (PUFAs n-3) sobre o desempenho e a resposta imunológica de frangos de corte frente a um desafio antigênico. Foram comparadas dietas formuladas com $7 \%$ de óleo de soja (OS), linhaça (OL) ou sardinha (OP), fornecidas a 240 frangos da linha- 
gem Cobb, divididos em 24 grupos de 10 aves cada, num arranjo experimental 3x2 (3 tipos de óleo e aves vacinadas ou não vacinadas) e 4 repetições. 0 óleo de soja é rico em ácido linoleico, um PUFA n-6, o óleo de linhaça é fonte de ácido alfa-linolênico, um PUFA n-3, e o óleo de sardinha, de outros PUFAs n-3, como os ácidos eicosapentaenoico e docosahexaenoico. 0 consumo de ração, o ganho de peso e a conversão alimentar foram avaliados aos 21, 35 e 42 dias. Aos 7 e aos 21 dias de idade, metade das aves recebeu vacina contra doença de Newcastle. Quinze dias após a imunização, avaliou-se a produção de anticorpos pelo método de ELISA, expressa pela densidade óptica a $450 \mathrm{~nm}$ (D.0. $450 \mathrm{~nm}$ ). Apenas as aves alimentadas com ração contendo OS apresentaram maior imunidade humoral $(\mathrm{P}<0,05)$ após a vacinação. A resposta linfoproliferativa das aves, que expressa a imunidade celular, foi maior entre as aves vacinadas, em comparação às aves não vacinadas $(\mathrm{P}<0,05)$, independentemente do óleo utilizado. A fonte de óleo da ração ou a vacinação não influenciaram o ganho de peso das aves $(\mathrm{P}>0,05)$. Entre as aves que receberam dieta com $\mathrm{OS}$, as aves vacinadas apresentaram pior conversão alimentar $(\mathrm{P}<0,05)$. Nos grupos que consumiram ração com OL ou OP, a vacinação não influenciou a conversão alimen$\operatorname{tar}(\mathrm{P}>0,05)$, considerando todo o período experimental. A utilização de óleo rico em PUFA n-6 na dieta de frangos de corte aumentou a resposta humoral, mas não influenciou a resposta celular frente a um desafio antigênico.

TERMOS DE INDEXAÇÃO: Óleo de linhaça, óleo de sardinha, óleo de soja, resposta celular, resposta humoral.

\section{INTRODUÇÃO}

A evolução da avicultura é fundamentada na constante evolução genética e na produção de linhagens de frangos com potencial produtivo cada vez maior, o que exige a formulação de dietas com elevada densidade energética (Fascina 2007). Por apresentar elevada concentração energética e baixo custo por unidade de energia, os óleos são ingredientes cada vez mais empregados na formulação de ração de frangos de corte (Junqueira et al. 2005), visando atender seu potencial de crescimento rápido. Além disso, constituem-se em fonte de ácidos graxos poli-insaturados essenciais (Andrade \& Carmo 2006), como o ácido linoleico e o ácido $\alpha$-linolênico. 0 primeiro é encontrado nas sementes de plantas oleaginosas, principalmente nos óleos de soja, milho, girassol e nas castanhas (Youdim et al. 2000).

0 ácido linoleico é convertido em ácido araquidônico e ambos integram o grupo de ácidos graxos poli-insaturados ômega-6 (PUFAs n-6). 0 ácido araquidônico é precursor da síntese de eicosanoides (Murakami et al. 2008) nos tecidos, sendo responsáveis pela formação especificamente das prostaglandinas da série 2, tromboxano A (TXA) e leucotrienos da série 4, mediadores bioquímicos potentes envolvidos na inflamação, infecção, lesão tecidual, modulação do sistema imune e agregação plaquetária (Hirayama et al. 2006). 0 ácido $\alpha$-linolênico tem como principais fontes as plantas e animais marinhos, principalmente os fitoplânctons, as algas e os óleos de peixes, mas também podem ser encontrados nos óleos vegetais de linhaça e canola (You- dim et al. 2000). O fitoplâncton, que se constitui na base da cadeia alimentar dos oceanos, sintetiza os ácidos eicosapentaenoico (EPA) e docosahexaenoico (DHA), os quais são encontrados em grande concentração nos óleos de peixes de águas frias e profundas, como cavala, sardinha, salmão e truta (Connor 2000). Os ácidos graxos $\alpha$-linolênico, EPA e DHA pertencem ao grupo de ácidos graxos poli-insaturados ômega-3 (PUFAs n-3), geralmente associados à prevenção de doenças cardiovasculares (Murakami et al. 2008).

A FAO recomenda que a ingestão de ácido linoleico corresponda a 3\% da energia total da dieta e a de ácido linolênico, entre 0,5\% e 1\%. A proporção recomendada entre PUFA n-6 e PUFA n-3 na dieta varia desde 3:1 até 10:1 (Kang 2003). A necessidade desse balanceamento entre os PUFA n-6 e n-3 se deve ao fato de que há uma competição das mesmas enzimas, dessaturases e alongases, pelos ácidos linoleico e $\alpha$-linolênico. A enzima limitante dessas reações é a dessaturase, que apresenta maior afinidade com os substratos mais insaturados, o que resulta em uma maior probabilidade da síntese de PUFA n-3, uma vez que o precursor desse grupo, o ácido linolênico, possui três insaturações, enquanto o ácido linoleico possui apenas duas (Simopoulos 2002).

Muitos estudos têm sido realizados com objetivo de investigar os efeitos da ingestão de ácidos graxos poli-insaturados sobre a resposta imune de humanos e animais, sendo poucos desses estudos direcionados às espécies aviárias. Nos trabalhos já publicados que abordam o tema, não se verificou um completo esclarecimento sobre a influência dos PUFA n-3 e n-6 na ação de eicosanoides e citocinas. Além disso, os resultados encontrados por diferentes autores são contraditórios, alguns relatand o a supressão da resposta imune humoral ou celular em dietas ricas em PUFA n-3, e outros, o estímulo à produção de imunoglobulinas ou resposta celular. Sijben et al. (2001) ressaltam, em seu trabalho, que esses resultados contraditórios podem ser atribuídos a vários fatores, como a utilização de diferentes antígenos na estimulação da resposta imune, o uso de diferentes espécies, ou, ainda, de diferentes linhagens dentro de uma mesma espécie. Assim, é importante que novos estudos sejam realizados a fim de se esclarecer os efeitos dos ácidos graxos essenciais na resposta imunológica de frangos de corte.

0 objetivo deste estudo foi avaliar comparativamente a influência da utilização de óleos ricos em PUFA n-6 ou n-3 na dieta de frangos de corte sobre o desempenho e a resposta humoral e celular frente a um desafio antigênico.

\section{MATERIAL E MÉTODOS}

Foram utilizadas 240 aves da linhagem comercial Cobb, machos, criados em galpão climatizado, com monitoração de temperatura, umidade relativa e velocidade do ar durante os 42 dias de período experimental. Adotou-se um programa de iluminação artificial de 23 horas de luz por 1 hora de escuro.

Foi utilizado um delineamento inteiramente casualizado, em esquema fatorial $3 \times 2$ ( 3 fontes de óleo $\mathrm{x}$ aves vacinadas ou não vacinadas), totalizando 6 tratamentos, com 4 repetições e 10 aves por repetição. As aves foram distribuídas em 24 boxes de $4,6 \mathrm{~m}^{2}$, sobre cama de maravalha, com livre acesso à água e ração formu- 
Quadro 1. Composição das rações basais para frangos de corte (\%)

\begin{tabular}{lccc}
\hline Ingredientes & $\begin{array}{c}\text { Ração Inicial } \\
(1-21 \text { dias })\end{array}$ & $\begin{array}{c}\text { Ração Crescimento } \\
\text { (22-35 dias) }\end{array}$ & $\begin{array}{c}\text { Ração Terminação } \\
(36-42 \text { dias })\end{array}$ \\
\hline Milho em grão & 49,11 & 54,26 & 57,49 \\
Farelo de soja (45\% PB) & 37,90 & 31,22 & 26,88 \\
Óleo* & 7,00 & 7,00 & 7,00 \\
Inerte (areia lavada) & 2,24 & 4,41 & 5,90 \\
Fosfato bicálcico & 2,00 & 1,23 & 1,05 \\
Calcário calcítico & 0,65 & 1,08 & 0,99 \\
Suplemento vitamínico e mineral** & 0,50 & 0,50 & 0,50 \\
Sal comum & 0,21 & 0,18 & 0,13 \\
DL-metionina & 0,20 & 0,09 & 0,04 \\
L- Lisina HCL & 0,19 & 0,03 & 0,02 \\
Composição calculada & & & 3.200 \\
Energia Metabolizável (kcal/kg) & 3.200 & 20,00 & 18,14 \\
Proteína bruta & 23,00 & 9,37 & 9,45 \\
Extrato etéreo & 9,25 & 0,90 & 0,80 \\
Cálcio & 1,00 & 0,35 & 0,30 \\
Fósforo disponível & 0,50 & &
\end{tabular}

*Os óleos de soja, linhaça e sardinha foram adicionados à ração na proporção de 7\%, conforme o tratamento e misturados no momento do preparo das rações experimentais. ** Composição do suplemento vitaminico e mineral (quantidade/kg do produto): Ração inicial: vit. A = 1.670.000 U.I.; vit. D3 = 335.000 U.I.; vit. E = 2.500mg; vit. K3 = 417mg; vit. B1 = 250mg; vit. B2 = 835 mg; vit. B6 = 250mg; vit. B12=2.000mcg; ácido fólico $=100 \mathrm{mg}$; biotina $=9 \mathrm{mg}$; ácido nicotínico $=5.835 \mathrm{mg}$; ácido pantotênico $=1.870 \mathrm{mg} ; \mathrm{Cu}=1.000 \mathrm{mg} ; \mathrm{Co}=17 \mathrm{mg} ; \mathrm{I}=170 \mathrm{mg} ; \mathrm{Fe}=8.335 \mathrm{mg} ; \mathrm{Mn}=$ $10.835 \mathrm{mg} ; \mathrm{Zn}=7.500 \mathrm{mg} ; \mathrm{Se}=35 \mathrm{mg}$; cloreto de colina $50 \%=116.670 \mathrm{mg}$; metionina $=250.000 \mathrm{mg}$; coccidiostático $=13.335 \mathrm{mg}$; promotor de crecimento $=13.335 \mathrm{mg}$; antioxidante $=2.000 \mathrm{mg}$. Ração crescimento: vit. A = 1.335 .000 U.I.; vit. D3 = 300.000 U.I.; vit. E = 2.000mg; vit. K3 = 335mg; vit. B1 = 167mg; vit. B2 = 670mg; vit. B6 = 170mg; vit. B12 = $1.670 \mathrm{mcg}$; ácido fólico = 67mg; biotina = 7mg; ácido nicotínico = 4.670mg; ácido pantotênico = 1.870mg; Cu = 1.000mg; Co = 17mg; I = 170mg; Fe = $8.335 \mathrm{mg} ; \mathrm{Mn}=10.835 \mathrm{mg}$; $\mathrm{zn}=7.500 \mathrm{mg} ; \mathrm{Se}=35 \mathrm{mg}$; cloreto de colina $50 \%=$ $83.340 \mathrm{mg}$; metionina $=235.000 \mathrm{mg}$; coccidiostático $=10.000 \mathrm{mg}$; promotor de crescimento $=10.000 \mathrm{mg}$; antioxidante $=2.000 \mathrm{mg}$. Ração terminação: vit. A = 1.670 .000 U.I.; vit. D3 = 335.000 U.I.; vit. $\mathrm{E}=2.335 \mathrm{mg}$; vit. $\mathrm{K} 3=400 \mathrm{mg}$; vit. $\mathrm{B} 1=100 \mathrm{mg}$; vit. $\mathrm{B} 2=800 \mathrm{mg}$; vit. $\mathrm{B} 6=200 \mathrm{mg}$; vit. $\mathrm{B} 12=$ $2.000 \mathrm{mcg}$; ácido fólico $=67 \mathrm{mg}$; biotina $=7 \mathrm{mg}$; ácido nicotínico $=5.670 \mathrm{mg}$; ácido pantotênico $=2.000 \mathrm{mg} ; \mathrm{Cu}=2.000 \mathrm{mg} ; \mathrm{Co}=27 \mathrm{mg} ; \mathrm{I}=270 \mathrm{mg} ; \mathrm{Fe}$ $=16.670 \mathrm{mg} ; \mathrm{Mn}=17.335 \mathrm{mg} ; \mathrm{Zn}=12,000 \mathrm{mg} ; \mathrm{Se}=70 \mathrm{mg}$; cloreto de colina 50\% = 100.000mg; metionina $=235.000 \mathrm{mg} ;$ antioxidante $=2.000 \mathrm{mg}$.

lada segundo especificações do National Research Council (NRC, 1994) para as fases inicial, de crescimento e terminação. Todos os animais receberam ração contendo a mesma porcentagem de óleo. Conforme cada tratamento, a ração foi formulada com óleo de soja, linhaça ou sardinha (Quadro 1).

Metade das aves foi vacinada aos 7 e 21 dias de idade contra a doença de NewCastle, recebendo uma gota ocular de suspensão vacinal de vírus vivo tipo B1, amostra La Sota (New Vac-LS ${ }^{\circledR}$, da Fort Dodge), permanecendo a outra metade sem vacinação.

Avaliação do desempenho. Aos 21, 35 e 42 dias de experimento, as aves e a ração foram pesadas para avaliação do ganho de peso, consumo de ração e conversão alimentar.

Avaliação da resposta imunológica. Para a avaliação da resposta imune, aos 35 dias de idade (14 dias após o término da vacinação), foram abatidas duas aves por repetição, totalizando 8 aves para cada tratamento. 0 sangue foi coletado por punção cardíaca, de forma asséptica, para avaliação de anticorpos contra vírus de Newcastle (soro) e proliferação de linfócitos T.

Resposta humoral. Os níveis de anticorpos específicos contra o vírus de Newcastle foram avaliados pelo método ELISA, por meio da utilização de kits comerciais (Newcastle Disease Antibody Test Kit, da IDEXX Lab. Inc., Maine, USA), seguindo a recomendação do fabricante. Todos os valores obtidos foram calculados conforme descrito pelo fabricante e os resultados foram expressos em densidade óptica (D.O.).

Resposta celular. Para a avaliação da imunidade celular, foi realizado o isolamento das células mononucleares de sangue periférico por gradiente de densidade, por meio da utilização do kit Ficoll-Paque PLUS (Amersham Biosciences, Fairfield, USA) seguindo as recomendações do fabricante. Posteriormente realizou-se a contagem das células em câmara de Neubauer. As células foram cultivadas em meio RPMI-1640 (Sigma Aldrich, Missouri, USA) suplementado com $10 \%$ de soro fetal bovino (Gibco Invi- trogen, Califórnia, USA) e com os antibióticos penicilina (100 IU/ $\mathrm{ml}$ ) (Gibco Invitrogen, Califórnia, USA) e estreptomicina (100 $\mu \mathrm{g} /$ $\mathrm{ml}$ ) (Gibco Invitrogen, Califórnia, USA) na presença do mitógeno Phytohemoaglutinina $(50 \mu \mathrm{g} / \mathrm{ml})$ (Gibco Invitrogen, Califórnia, USA) em estufa com $5 \%$ de $\mathrm{CO}_{2}$ a $40^{\circ} \mathrm{C}$ por $72 \mathrm{~h}$. Após o período de incubação, a resposta linfoproliferativa foi determinada por citometria utilizando-se o kit CellTrace ${ }^{T M}$ CFSE Cell proliferation (Invitrogen, Califórnia, USA) de acordo com as recomendações do fabricante.

A análise da proliferação celular foi feita pelo programa Cytosoft versão 4.1 - Guava Expressplus. Os resultados foram expressos como Índice de Proliferação Celular (IPC) e obtidos pela divisão entre a contagem de proliferação celular/contagem de células mãe.

Análise estatística. Os resultados obtidos foram submetidos à análise de variância (ANOVA) e as médias foram comparadas pelo teste $t$ para comparação múltipla com $5 \%$ de significância (Zar 1992). A análise estatística foi efetuada empregando-se o pacote estatístico SAS (SAS 2001).

O modelo utilizado foi:

$$
Y_{i j}=\mu+O_{i}+V_{j}+O V_{i j}+e_{i j}
$$

onde: $\mathrm{Y}=$ valor da variável resposta; $\mu=$ média geral; $\mathrm{O}_{\mathrm{i}}=$ efeito do óleo i ( $\mathrm{i}=$ soja, linhaça ou sardinha); $\mathrm{V}_{\mathrm{j}}=$ efeito do grupo $\mathrm{j}$ ( $\mathrm{j}$ = vacinados e não vacinados); $\mathrm{OV}_{\mathrm{ij}}=$ efeito da interação entre grupo i x j; $\mathrm{e}_{\mathrm{ij}}=$ erro. Foi considerada diferença significativa, se $P$ $\leq 0,05$.

\section{RESULTADOS}

No Quadro 2 são apresentados os parâmetros de desempenho das aves até os 21, 35 e 42 dias de idade. A média do consumo alimentar até os 21 dias não diferiu significativa- 
Quadro 2. Desempenho produtivo médio das aves de acordo com o óleo e a vacinação aos 21, 35 e 42 dias de idade

\begin{tabular}{lcccccccccc}
\hline & \multicolumn{3}{c}{ Consumo Alimentar (g) } & \multicolumn{3}{c}{ Ganho de Peso (g) } & \multicolumn{3}{c}{ Conversão Alimentar } \\
\hline $\begin{array}{l}\text { Tratamentos } \\
\text { Óleos }\end{array}$ & $1-21 \mathrm{~d}$ & $1-35 \mathrm{~d}$ & $1-42 \mathrm{~d}$ & $1-21 \mathrm{~d}$ & $1-35 \mathrm{~d}$ & $1-42 \mathrm{~d}$ & $1-21 \mathrm{~d}$ & $1-35 \mathrm{~d}$ & $1-42 \mathrm{~d}$ \\
Linhaça & $913^{\mathrm{a}}$ & $3617^{\mathrm{a}}$ & $4984^{\mathrm{b}}$ & $665^{\mathrm{a}}$ & $2459^{\mathrm{a}}$ & $2865^{\mathrm{a}}$ & $1,37^{\mathrm{a}}$ & $1,47^{\mathrm{a}}$ & $1,74^{\mathrm{a}}$ \\
Sardinha & $954^{\mathrm{a}}$ & $3847^{\mathrm{a}}$ & $5321^{\mathrm{a}}$ & $687^{\mathrm{a}}$ & $2561^{\mathrm{a}}$ & $2934^{\mathrm{a}}$ & $1,39^{\mathrm{a}}$ & $1,50^{\mathrm{a}}$ & $1,81^{\mathrm{a}}$ \\
Soja & $903^{\mathrm{a}}$ & $3687^{\mathrm{a}}$ & $4998^{\mathrm{b}}$ & $650^{\mathrm{a}}$ & $2474^{\mathrm{a}}$ & $2812^{\mathrm{a}}$ & $1,39^{\mathrm{a}}$ & $1,49^{\mathrm{a}}$ & $1,78^{\mathrm{a}}$ \\
Vacinação & & & & & & & & & & \\
Vacinados & $938^{\mathrm{a}}$ & $3813^{\mathrm{a}}$ & $5145^{\mathrm{a}}$ & $676^{\mathrm{a}}$ & $2522^{\mathrm{a}}$ & $2843^{\mathrm{a}}$ & $1,39^{\mathrm{a}}$ & $1,51^{\mathrm{a}}$ & $1,81^{\mathrm{a}}$ \\
Não Vacinados & $909^{\mathrm{a}}$ & $3621^{\mathrm{b}}$ & $5057^{\mathrm{a}}$ & $658^{\mathrm{a}}$ & $2474^{\mathrm{a}}$ & $2897^{\mathrm{a}}$ & $1,38^{\mathrm{a}}$ & $1,46^{\mathrm{b}}$ & $1,74^{\mathrm{a}}$ \\
CV (\%) & 6,39 & 5,94 & 5,78 & 7,19 & 5,32 & 4,32 & 3,86 & 2,51 & 2,89 \\
ANOVA & Pr F & & & & & & & & & \\
Óleo (0) & 0,2161 & 0,1305 & 0,0586 & 0,3167 & 0,2820 & 0,1720 & 0,7356 & 0,2467 & 0,0371 \\
Vacinação (V) & 0,2534 & 0,0466 & 0,4734 & 0,3812 & 0,3953 & 0,3064 & 0,6800 & 0,0048 & 0,0071 \\
O x V & 0,8359 & 0,7484 & 0,8249 & 0,5083 & 0,9106 & 0,1701 & 0,0228 & 0,1302 & 0,0338
\end{tabular}

$\overline{\operatorname{Pr}>\mathrm{F}}=$ Nível descritivo; $\mathrm{CV}=$ Coeficiente de Variação. Médias seguidas de letras diferentes diferem entre si pelo teste $t(\mathrm{P}<0,05)$.

mente em nenhum dos tratamentos $(P>0,05)$. No período de 1 a 35 dias, não foi verificada diferença de consumo associada à fonte de óleo da ração, mas as aves vacinadas consumiram mais ração que as aves não vacinadas $(\mathrm{P}<0,05)$. Considerando todo o período de criação, de 1 a 42 dias, as aves suplementadas com óleo de sardinha apresentaram um consumo de ração maior que os demais grupos $(\mathrm{P}<0,05)$. 0 consumo das rações contendo óleo de soja ou óleo de linhaça não diferiu $(P>0,05)$ entre si em nenhum dos períodos avaliados.

0 ganho de peso das aves não diferiu significativamente $(P>0,05)$ nem entre as aves alimentadas com as rações contendo as diferentes fontes de óleo, nem entre as aves vacinadas e não vacinadas, em nenhum dos períodos avaliados.

No período de 1 a 35 dias de idade, a conversão alimentar não foi influenciada pela fonte de óleo da ração $(P>0,05)$ e apresentou média mais elevada para as aves vacinadas do que para as não vacinadas $(\mathrm{P}<0,05)$. Já nos períodos de 1 a 21 dias e de 1 a 42 dias de idade, a interação entre os fatores (fonte de óleo $\mathrm{x}$ vacinação) foi significativa $(\mathrm{P}<0,05)$. Por isso, essas interações foram desdobradas e são apresentadas no Quadro 3, onde pode ser observado que a vacinação teve influência na conversão alimentar apenas nas aves alimentadas com ração contendo óleo de soja, com médias mais elevadas para as aves vacinadas do que para as não vacinadas, nos dois períodos avaliados $(\mathrm{P}<0,05)$. Entre as aves alimentadas com ração contendo óleo de linhaça ou óleo de sardinha, a vacinação não influenciou a conversão alimentar $(P>0,05)$. Entre as aves vacinadas, a conversão alimentar das que consumiram ração com óleo de soja foi mais elevada do que daquelas que consumiram ração com óleo de linhaça, nos dois períodos avaliados. A média das aves que consumiram óleo de sardinha na ração foi intermediária, não diferindo da média dos outros dois tratamentos. Entre as aves não vacinadas, no período de 1 a 21 dias não houve diferença na conversão alimentar associada à fonte de óleo da dieta $(\mathrm{P}>0,05)$. Considerando o período de 1 a 42 dias, a conversão alimentar das aves submetidas à dieta com óleo de sardinha foi mais elevada do que daquelas que consumiram ração com óleo de soja ou linhaça.
Quadro 3. Desdobramento da interação óleo x vacinação na conversão alimentar das aves aos 21 e 42 dias de idade

\begin{tabular}{cccc}
\hline \multicolumn{3}{c}{ Conversão Alimentar } \\
\hline $\begin{array}{c}\text { Período } \\
\text { (dias) }\end{array}$ & Óleos & $\begin{array}{c}\text { Vacinados } \\
\text { (Média } \pm \text { Desvio Padrão) }\end{array}$ & $\begin{array}{c}\text { Não Vacinados } \\
\text { (Média } \pm \text { Desvio Padrão) }\end{array}$ \\
\hline 21 & Linhaça & $1,347 \pm 0,034 \mathrm{bA}$ & $1,400 \pm 0,046 \mathrm{aA}$ \\
& Sardinha & $1,383 \pm 0,087 \mathrm{abA}$ & $1,404 \pm 0,061 \mathrm{aA}$ \\
& Soja & $1,442 \pm 0,476 \mathrm{aA}$ & $1,340 \pm 0,016 \mathrm{aB}$ \\
42 & Linhaça & $1,765 \pm 0,042 \mathrm{bA}$ & $1,716 \pm 0,033 \mathrm{bA}$ \\
& Sardinha & $1,812 \pm 0,064 \mathrm{abA}$ & $1,813 \pm 0,070 \mathrm{aA}$ \\
& Soja & $1,851 \pm 0,063 \mathrm{aA}$ & $1,707 \pm 0,005 \mathrm{bB}$
\end{tabular}

Médias seguidas de mesma letra, minúscula na coluna e maiúscula na linha, não diferem entre si pelo teste $t(P>0,05)$.

Quadro 4. Imunidade humoral, avaliada pelo método ELISA, expressa em densidade óptica (D.0), e imunidade celular, expressa pelo Índice de Proliferação Celular (I.P.C), em aves aos 42 dias de idade

\begin{tabular}{lcccc}
\hline & \multicolumn{2}{c}{ D.O. (Média \pm Desvio Padrão) } & \multicolumn{2}{c}{ I.P.C. (Média \pm Desvio Padrão) } \\
\hline \multicolumn{1}{c}{ Óleo } & Vacinado & Não vacinado & Vacinado & Não vacinado \\
\hline Linhaça & $0,249 \pm 0,216^{\mathrm{bA}}$ & $0,100 \pm 0,081^{\mathrm{aA}}$ & $1,040 \pm 0,500^{\mathrm{aA}}$ & $0,255 \pm 0,135^{\mathrm{aB}}$ \\
Sardinha & $0,218 \pm 0,177^{\mathrm{bA}}$ & $0,106 \pm 0,081^{\mathrm{A}}$ & $1,239 \pm 0,506^{\mathrm{AA}}$ & $0,462 \pm 0,526^{\mathrm{aB}}$ \\
Soja & $0,740 \pm 0,372^{\mathrm{aA}}$ & $0,228 \pm 0,113^{\mathrm{aB}}$ & $1,550 \pm 0,723^{\mathrm{aA}}$ & $0,488 \pm 0,233^{\mathrm{aB}}$
\end{tabular}

Médias seguidas de mesma letra, minúscula na coluna e maiúscula na linha, não diferem entre si pelo teste $t(P>0,05)$.

Para avaliação da resposta imune humoral e celular, foi utilizada a vacina contra o vírus de Newcastle como desafio antigênico. No Quadro 4 estão expressas as médias e os respectivos desvios padrão dos valores de densidade óptica (D.O.) obtidos no teste de ELISA e Índice de Proliferação Celular (IPC) obtidos após estímulo pelo mitógeno fitohemoaglutinina.

A avaliação da resposta humoral demonstrou a influência da fonte de óleo da dieta sobre a resposta vacinal dos frangos. Nas aves não vacinadas, não houve diferença significativa para os valores de D.O. entre os grupos que consumiram ração com óleo de linhaça, sardinha ou soja. Após a vacinação, apenas o grupo que recebeu óleo de soja apresentou um aumento significativo $(\mathrm{P}<0,05)$ da produção de imunoglobulinas. Entre as aves que consumiram ração com óleo de linhaça ou de sardinha, a média dos valores de D.O. não diferiu entre as aves vacinadas e não vacinadas $(\mathrm{P}>0,05)$. 
Na avaliação da imunidade celular, não foi observada diferença significativa na resposta linfoproliferativa de células $\mathrm{T}$ associada à fonte de óleo da dieta das aves $(\mathrm{P}>$ $0,05)$, mas a média das aves vacinadas foi significativamente maior do que das aves não vacinadas $(\mathrm{P}<0,05)$ em todas as dietas avaliadas.

\section{DISCUSSÃO}

A estimulação do sistema imune resulta na produção de uma série de citocinas que promovem o aumento da utilização de energia (Klasing \& Johnstone 1991). Neste experimento, foi realizada a vacinação contra doença de Newcastle aos 7 e aos 21 dias de idade, fazendo com que a demanda energética provocada pela resposta imunológica coincidisse com a fase de grande desenvolvimento corporal das aves, o que resultou numa maior demanda de nutrientes e, consequentemente, maior ingestão de alimentos pelas aves vacinadas, observada no período de 1 a 35 dias de idade $(\mathrm{P}<0,05)$. Como consequência, nesse mesmo período, a média da conversão alimentar das aves vacinadas foi mais elevada do que das aves não vacinadas $(\mathrm{P}<0,05)$, conforme demonstrado no Quadro 2. Por outro lado, o ganho de peso das aves não foi influenciado pela vacinação em nenhum dos períodos avaliados ( $\mathrm{P}>0,05)$.

A fonte de óleo da dieta também não influenciou o ganho de peso em nenhum dos períodos avaliados. Maroufyan et al. (2012) também não observaram diferença no ganho de peso corporal de frangos de corte alimentados com ração contendo 7\% de óleo de peixe, óleo de milho ou óleo de girassol antes e após as aves serem submetidas a um desafio antigênico. 0 mesmo resultado é descrito por Parmentier et al. (1997) que, utilizando óleo de peixe para avaliar a influência de diferentes concentrações de ácidos graxos ômega-3 sobre o desempenho de frangos de corte, não verificaram diferença no ganho de peso. A fonte de óleo da dieta também pode interferir nos parâmetros de desempenho devido a alterações organolépticas na ração. Alguns autores relataram diminuição de consumo com a utilização de óleo de peixe na ração, devido à sua baixa palatabilidade (Hulan et al. 1988, Pita 2007, Navidshad 2009). No entanto, neste experimento, o consumo de ração contendo óleo de sardinha foi maior do que das rações formuladas com óleos de soja ou linhaça $(\mathrm{P}<0,05)$, no período de 1 a 42 dias. Não foi observada diferença no consumo entre as rações contendo óleo de soja e linhaça, o que coincide com os resultados reportados por Korver \& Klasing (1998). Como o ganho de peso não diferiu entre os tratamentos, não tendo sido influenciado nem pela fonte de óleo da dieta nem pela vacinação, no mesmo período, de 1 a 42 dias, a média da conversão alimentar das aves alimentadas com ração contendo óleo de sardinha foi mais elevada, em função do consumo mais elevado $(\mathrm{P}<0,05)$.

$\mathrm{Na}$ avaliação da resposta humoral, foi observado que, após a vacinação, as aves que receberam óleo de linhaça ou sardinha não apresentaram aumento significativo na produção de imunoglobulinas. Resultado similar ao observado por Wang et al. (2000), Nayebpor et al. (2007) e Murakami et al. (2008) que, ao incluírem óleo de linhaça à dieta de frangos de corte, observaram diminuição na produção de anticorpos contra desafiantes imunológicos específicos. Entre as aves que consumiram ração contendo óleo de soja, ocorreu um aumento significativo $(\mathrm{P}<0,05)$ na produção de anticorpos em resposta à vacinação. Segundo Sijben et al. (2001), o consumo de óleos ricos em PUFAs n-6 favorece a resposta das citocinas séricas Th2 em relação às Th1. A produção de anticorpos em resposta à vacina é dependente de células Th2, sendo favorecida por dietas ricas em PUFAs n-6, enquanto a inclusão de PUFAs n-3 na dieta está associada à diminuição da resposta de anticorpos, como foi observado no presente estudo. Os anticorpos podem bloquear sítios antigênicos, proteger a mucosa de várias infecções, facilitar a retirada de antígenos do sangue, ativar o sistema complemento e facilitar a retirada de patógenos por citotoxicidade dependente de anticorpo.

Os resultados deste trabalho sugerem que, em situações em que é desejável o aumento de produção de anticorpos, o consumo de óleo de soja, como fonte de PUFAs n-6, é recomendado. 0 mecanismo pelo qual a produção de anticorpos foi aumentada não foi investigado, porém, sabe-se que o balanço entre PUFAs n-6 e PUFAs n-3 na dieta pode mudar a composição da membrana e alterar a sinalização intracelular e a expressão gênica, que afeta a produção de anticorpos. Numa dieta rica em PUFAS n-3, estes são incorporados às membranas celulares substituindo o ácido araquidônico, e a consequência dessa substituição é a menor produção de eicosanoides mediadores, como a PGE2 e o LTB4. A PGE2 poderá, em diferentes situações, inibir ou estimular a produção de imunoglobulinas pelas células $B$, através do estímulo à produção e interação de diferentes citocinas (He et al. 2001).

A resposta linfoproliferativa de células $\mathrm{T}$ ao mitógeno fitohemaglutinina das aves vacinadas foi maior que das aves não vacinadas $(\mathrm{P}<0,05)$, porém não foi observada diferença nas médias do Índice de Proliferação Celular (I.P.C) associada a fonte de óleo na dieta (Quadro 4). Estes resultados são semelhantes aos observados por Khatibjoo et al. (2011), que, alterando a composição de óleo na ração de frangos, também não observaram aumento de proliferação dos linfócitos.

A utilização de diferentes fontes de óleo na ração de frangos de corte não interferiu no ganho de peso das aves. 0 óleo de sardinha adicionado à ração promoveu aumento do consumo e teve efeito negativo sobre a conversão alimentar das aves, considerando todo o período experimental, até os 42 dias de idade. A resposta imune celular das aves à vacinação contra doença de Newcastle não foi influenciada pela fonte de óleo da dieta. A vacinação, independente da fonte de óleo, induziu resposta proliferativa dos linfócitos. Tal resposta ocorre em decorrência da produção de IL-2, citocina que faz parte da resposta imunológica em aves vacinadas. A utilização de óleo rico em PUFA n-6 na dieta de frangos de corte aumentou a resposta imune humoral das aves à vacinação contra a doença de Newcastle, em comparação a dietas contendo óleos ricos em PUFAs n-3.

\section{REFERÊNCIAS}

Andrade P.M.M. \& Carmo M.G.T. 2006. Ácidos graxos n-3: um link entre eicosanoides, inflamação e imunidade. INJC, UFRJ, 8(3):135-143. 
Connor W.E. 2000. Importance of $n-3$ fatty acids in health and disease. Am. J. Clin. Nutr. 71(1):171-175.

Fascina V.B. 2007. Valor energético, desempenho, lipídios séricos e composição corporal de frangos de corte recebendo óleo de soja e sebo bovino em diferentes combinações. Dissertação de Mestrado, Universidade Federal de Mato Grosso do Sul, Campo Grande, MS. 57p.

He X., Weyand C.M., Goronzy J.J., Zhong W. \& Stuart J.M. 2001. Bi-directional modulation of $\mathrm{T}$ cell-dependent antibody production by prostaglandin-E2. Int. Immunol. 14:69-77.

Hirayama K.B., Speridião P.G.L. \& Neto U.F. 2006. Ácidos graxos poli-insaturados de cadeia longa. Electron. J. Pedriatr. Gastroenterol. Nutr. Livest. Dis. 10(3). Disponível em <http://www.e-gastroped.com.br/sep06/acidosgraxos.htm>

Hulan H.W., Ackman R.G., Ratnayake W.M.N. \& Proudfoot F.G. 1988. Omega-3 fatty acid levels and performance of broilers chickens fed redfish meal or redfish oil. Can. J. Anim. Sci. 68(1):533-547.

Junqueira O.M., Andreotti M.O., Araújo L.F., Duarte K.F., Cancherini L.C \& Rodrigues E.A. 2005. Valor energético de algumas fontes lipídicas determinado com frangos de corte. Revta Bras. Zootec. 34(6):23352339.

Kang J.X. 2003. The importance of omega-6/omega-3 fatty acid ratio in cell function. The gene transfer of omega-3 fatty acid desaturase. World Rev. Nutr. Diet. 92:23-36.

Khatibjoo A., Kermanshahi H., Golian A. \& Zaghari M. 2011. The effect of dietary n-6:n-3 ratio and sex on broilerbreeder immunity. Poult. Sci. 90(10):2209-2216.

Klasing K.C. \& Johnstone B.J. 1991. Monokines in growth and development. Poult. Sci. 70(8):1781-1789.

Korver D.R., Roura E. \& Klasing K.C. 1998. Effect of Dietary energy level and oil source on broiler performance and response to an inflammatory challenge. Poult. Sci. 77(8):1217-1227.

Maroufyan E., Kasim A., Ebrahimi M., Loh T.C., Bejo M.H., Zerihun H., Hosseni F., Goh Y.M. \& Farjam A.S. 2012. Omega-3 polyunsaturated fatty acids enrichment alters performance and immune response in infectious bursal disease challenged broilers. Lipids Health Dis. 11:15.
Murakami K.T.T., Pinto M.F. \& Lima V.M.F. 2008. Omega-3 fatty acids and broilers immunology. Vet. Zootec. 15:112.

Navidshad B. 2009. Effects of fish oil on growth performance and carcass characteristics of broiler chicks fed a low-protein diet. Int. J. Agr. Biol. 11(5):635-638.

Nayebpor M., Farhomand P. \& Hashemi A. 2007. Effects of differents levels of direct fed microbial (Primalac) on growth performance and humoral immune response in broiler chickens. J. Anim. Vet. Adv. 6(11):1308-1313.

NRC 1994. Nutrient Requirements of Poultry. National Research Council. $9^{\text {th }}$ ed. National Academy of Sciences, Washington, D.C. 155.

Parmentier H.K., Nieuwland M.G.B., Barwegen M.W., Kwakkel R.P. \& Schrama J.W. 1997. Dietary unsaturated fatty acids affect antibody responses and growth of chickens divergently selected for humoral responses to sheep red blood cells. Poult. Sci. 76(8):1164-1171.

Pita M.C.G. 2007. Fontes marinhas e vegetais de PUFAs na dieta de galinhas poedeiras: efeito na composição lipídica da gema do ovo e tempo de incorporação dos ácidos graxos. Tese de Doutorado, Faculdade de Medicina Veterinária e Zootecnia, Universidade de São Paulo, São Paulo. $136 \mathrm{p}$.

SAS 2001. Statistical Analysis System User's Guide: stat. version. $8^{\text {th }}$ ed. SAS Institute, Cary. 1464p.

Wang Y.W., Field C.J. \& Sim J.S. 2000. Dietary polyunsaturated fatty acids alter lymphocyte subset proportion and proliferation, serum immunoglobulin G concentration, and immune tissue development in chicks. Poult. Sci. 79(12):1741-1748.

Simopoulos A.P. 2002. The importance of the ratio of omega-6/omega-3 essential fatty acids. Biomed. Pharmacother. 56(8):365-379.

Sjben J.W., Schrama J.W., Parmentier H.K., Van der Poel J.J. \& Klasing K.C. 2001. Effects of dietary polyunsaturated fatty acids on in vivo splenic cytokine mRNA expression in layer chicks immunized with Salmonella typhimurium lipopolysaccharide. Poult. Sci. 80(8):1164-1170.

Youdim M.B., Gassen M., Gross A., Mandel S. \& Grünblatt E. 2000. Iron chelating, antioxidant and cytoprotective properties of dopamine receptor agonist; apomorphine. J. Neural Transm. 58(Suppl.):83-96.

Zar J.H. 1992. Biostatistical Analysis. $4^{\text {th }}$ ed. Prentice-Hall, New Jersey. 930p. 